\title{
Regional differences in technology : theory and empirics
}

Citation for published version (APA):

Caniëls, M. C. (1996). Regional differences in technology : theory and empirics. MERIT, Maastricht Economic Research Institute on Innovation and Technology. MERIT Research Memoranda No. 005 https://doi.org/10.26481/umamer.1996005

Document status and date:

Published: 01/01/1996

DOI:

10.26481/umamer.1996005

Document Version:

Publisher's PDF, also known as Version of record

\section{Please check the document version of this publication:}

- A submitted manuscript is the version of the article upon submission and before peer-review. There can be important differences between the submitted version and the official published version of record.

People interested in the research are advised to contact the author for the final version of the publication, or visit the DOI to the publisher's website.

- The final author version and the galley proof are versions of the publication after peer review.

- The final published version features the final layout of the paper including the volume, issue and page numbers.

Link to publication

\footnotetext{
General rights rights.

- You may freely distribute the URL identifying the publication in the public portal. please follow below link for the End User Agreement:

www.umlib.nl/taverne-license

Take down policy

If you believe that this document breaches copyright please contact us at:

repository@maastrichtuniversity.nl

providing details and we will investigate your claim.
}

Copyright and moral rights for the publications made accessible in the public portal are retained by the authors and/or other copyright owners and it is a condition of accessing publications that users recognise and abide by the legal requirements associated with these

- Users may download and print one copy of any publication from the public portal for the purpose of private study or research.

- You may not further distribute the material or use it for any profit-making activity or commercial gain

If the publication is distributed under the terms of Article $25 \mathrm{fa}$ of the Dutch Copyright Act, indicated by the "Taverne" license above, 


\title{
Regional Differences in Technology \\ Theory and Empirics
}

\author{
By \\ Marjolein C.J. Caniëls \\ (MERIT)
}

May 1996

\begin{abstract}
The aim of this paper is, on the one hand, to give a review of several streams in the literature which differ with respect to the extent they assume knowledge to spread over regions. On the other hand, this paper shows the extent to which these theories are supported empirically.

The regional neoclassical growth model focuses on the immediate diffusion of technological knowledge. Alternative theories like cumulative causation and imperfect diffusion theories focus on the issue that technology gaps between regions will persist over time. Cumulative causation assumes that there exists no diffusion of knowledge, while imperfect diffusion theories assume that diffusion will take place, though slowly.

These theoretical insights lead to several testable hypotheses on the presence and the development over time of regional technology gaps. This paper attempts to use a new set of data on R\&D in the European Union to explore this field. Evidence from regional R\&D statistics will be used to highlight differences in technological activity between the regions within the leading European economies. Also the factors that are proposedly related to the relative technological activity of a region are analysed, in addition to the long term implications of technology gaps.
\end{abstract}




\section{Introduction}

Over the years a lot of attention has been paid to explaining regional differences in growth. Less attention was directed towards the issue of knowledge diffusion, at least by economists. Mainly, this was due to the enormous impact of neoclassical theory in all segments of economic theory. Under the neoclassical model, technology was assumed to spread immediately and be "under competition available to all" (Borts and Stein, 1964, p. 8). Extending the neoclassical line of reasoning, it can be argued that knowledge is easy codifyable in blueprints, patents, etcetera. Therefore, knowledge can be accessed easily everywhere, i.e. knowledge spreads immediately and technology gaps between geographical locations do not exist.

Today, information communication has lead to a substantial increase in the spread of knowledge. Features such as electronic mail, the world wide web and newsgroups enable people to get access to information all over the world in a few seconds. However, to argue that all knowledge spreads immediately, as in the neoclassical view, would be wrong. Now, more than ever, the impact of tacit knowledge becomes visible. Tacit knowledge is knowledge which is mainly embedded in persons, by the specific skills people have acquired over time. A characteristic of tacit knowledge is that it is very difficult, if not impossible, to communicate or document this knowledge. The main way to diffuse this kind of knowledge is by learning. The large availability of information in these days, stimulates the interaction between codified knowledge, which is easy accessible and can be accumulated by everyone, and tacit knowledge, which is embedded in persons. This process leads to more learning, which for a part will be codified into new machines. So the process of technological progress consists of, on the one hand, trying to accumulate codified knowledge and process it into tacit knowledge, and on the other hand codifying the new (tacit) knowledge into blueprints and patents.

When applying these insights to the regional view of the economy, it becomes clear that the traditional neoclassical view is invalid. Tacit knowledge will be kept in firms, so knowledge will stay with one geographical location and not diffuse easily. Therefore, technology gaps between regions will persist. The only knowledge that does diffuse, is the superficial knowledge, which provides others with general information but not specific details. It is like the cook gives you the ingredients but not the recipe to make a delicious meal.

In the literature the impact of tacit knowledge was acknowledged with the event of the application of the neoclassical model to regional economics. Only then, the assumption about technology became severely criticized. The question, which was raised by economists, is whether alternative models could explain reality better by paying more attention to the diffusion of knowledge. In course of time, various alternative models were developed, which assumed knowledge to spread imperfectly or not at all. In other words, the absence of technology gaps between regions, which was assumed by neoclassical economists, was questioned severely.

Since the alternative models take as a point of departure that technology gaps between regions exist, this arouses interest for the factors that are considered important in influencing the innovativeness of a region, in the different theories. For these factors explain the attractiveness of a region for innovative activity.

A first question that immediately comes to mind after studying these alternative theories is whether empirical evidence is to be found for the presence of technology gaps (which is the point of departure of these models). Furthermore, what are the factors that 
play a role in relation to innovativeness, i.e. are there certain characteristics of a region that make a region attractive for innovative activity? A further question concerns the long run implications of technology gaps for the economy as a whole. Will convergence or divergence appear in the long run distribution of $\mathrm{R} \& \mathrm{D}$ across regions?

The aim of this paper is to look closer at the models which have alternative assumptions about technology and then show the extent to which these theories are supported empirically. In order to do so this paper consists of two parts, a theoretical and an empirical one. The theoretical part of this paper will give an overview of how various streams of research incorporated knowledge diffusion over regions. First, in section II, the regional neoclassical growth theory will be discussed, which assumed knowledge to be perfectly mobile. Another extreme is to assume immobility of knowledge, i.e. technology stays within one region and therefore comes to the benefit of only this region. This assumption was made in cumulative causation models, which will be discussed in section III. In the literature a third class of models can be distinguished, namely models which assume knowledge to spread slowly. The speed and the sequence of diffusion depend on various factors in these models (see section IV).

Section V and VI will pay attention to the relation between theoretical and empirical part. Subsequently, the empirical part of this paper will present a few empirical methods aimed at testing some of the theories described in the first part of this paper. The first of the three empirical findings (section VII) is descriptive of nature, illustrating the 'stylized facts' of the distribution of knowledge creation through space. The purpose of using this method is to test for the presence of technology gaps. The second empirical operation lists for the relationship between $R \& D$ in a region and the presence of certain factors stressed by the theories in part one, like population density, economies of scale and higher education. This empirical operation will be discussed in section VIII. The third and final empirical operation (section IX) looks for the long run implications of the empirical relations found. By means of transition matrices it is investigated whether convergence or divergence would appear in the long run distribution of $\mathrm{R} \& \mathrm{D}$ across regions.

\section{Neoclassical theory}

The neoclassical growth model serves as the basic tool for understanding the growth process in advanced countries and has been applied in empirical studies of the sources of economic growth. Since the 1960s, many regional economists have tried to desaggregate the neoclassical growth model to a regional growth model. Borts (1960) can be noted as the first case of a regional neoclassical growth model. In his model the following assumptions were made: (i) The total supply of labour available to all regions together is fixed. The only way in which one region may employ more labour is through immigration from other regions; (ii) a single homogeneous output is produced in each region; (iii) there are zero transport costs between regions, so that the price of output is uniform; (iv) there are zero costs of converting output into capital goods; (v) the same production function exists in each region, being homogeneous of degree one in the inputs labour and capital, so technical knowledge is under competition available to all, diffusion is immediate.

It should be emphasized that the value of this neoclassical regional growth model depends heavily on the underlying assumptions, which are very unrealistic and in some cases even incompatible with the regional setting (Richardson, 1973, 1978a, 1978b). The assumption which perhaps raised most doubt about its amount of reality in a regional 
model was the assumption of immediate diffusion of knowledge, i.e. it was considered hard to maintain this assumption, taking into account the distance between the place of invention/innovation and the rest of the country. The issues of space and distance (and also the time needed to bridge the distance) are completely ignored within the traditional neoclassical model. By introducing regions in the model, many economists argued that the concepts of space and distance needed to be acknowledged, because only these concepts could bring a full understanding of the forces behind the differences in growth between regions (or nations when considering a more aggregated view) (Richardson, 1973). Besides labour and capital, for which the assumption of mobility is perhaps more appropriate ${ }^{1}$, the neoclassical model should also have paid attention to knowledge. It is this 'omission' that has become to be seen as the main limitation of the neoclassical regional growth model.

Regarding growth rate differentials, the neoclassical model, at least in its unaltered form $^{2}$, predicts convergence. In the pure aggregate neoclassical model, it can be shown that when differences in the growth rate of output between countries exist, these will disappear under the influence of differential capital accumulation, which can be generated by investments or by movements of production factors. When capital accumulation takes place through movements of production factors, as assumed in most of the regional literature, the process is as follows. It can be shown that the return to capital (marginal product of capital) is an inverse function of the capital-labour ratio and the wage rate (marginal product of labour) is a direct function of the capital labour ratio. Therefore, given identical production functions in all countries and capital accumulation through factor movements, labour will flow from low to high wage countries and capital will flow in the opposite direction. These flows will continue until all differences in the growth rate of output have disappeared (Richardson 1973, 1978a, 1978b), and the long run steady state and exogenously determined growth rates are reached (Barro and Sala-i-Martin, 1991). As Barro (1991) and Barro and Sala-i-Martin (1991, 1992) have demonstrated, the further economies are distanced from the steady state position, the faster they tend to converge towards this long-run steady state ${ }^{3}$.

Thus, applying this aggregated neoclassical view to regional models, a high capital/labour ratio in a region - caused by a difference in factor endowments - will lead to high wages and low rates of return to capital. Given identical production functions in all regions, this causes an inflow of labour and an outflow of capital in this region. These flows continue until factor returns are equalized in each region, thus, until the capital/labour ratio is brought back to its equilibrium value and the aggregate economy is in a steady state. This regional process will cause regional per capita income levels to converge, if at least certain additional assumptions are met (such as equal labour participation rates, property income distributed among regions in proportion to population) (Richardson, 1978a).

${ }^{1}$ Although capital is much more mobile than labour (Richardson, 1973).

2 As will be noticed in subsequent paragraphs, adjustment or manipulation of the assumptions of the neoclassical model can lead to other outcomes.

${ }^{3}$ In the long run steady state of a neoclassical growth model, the growth rate of output is equal to the growth rate of capital. For a further description of the dynamics of the neoclassical model is pointed to Solow (1970), Mankiw, Romer, Weil (1992) or Barro and Sala-i-Martin (1995). 
With respect to this reasoning a critical remark is in place. This far, it has been impossible to test the predictions of the neoclassical model properly, because of a lack of usable regional capital stock and capital yield data. The tests that were carried out have merely investigated whether there exists a convergence in regional per capita income levels (Richardson, 1978a) ${ }^{4}$. The results from these tests were put forward as giving support to the following hypotheses of the neoclassical model: (1) "the return to capital is inversely related to regional capital-labour ratios," and (2) "net capital flows are a function of differentials in the inter-regional rates of return on capital" (Richardson, 1978, p. 27). Obviously, results of empirical tests on convergence in per capita income levels only indirectly support these hypotheses and thereby the neoclassical model.

A second critical remark can be made with regard to the 'empirical support' of the neoclassical theory. Empirical tests indicated different outcomes (convergence or divergence) depending on the country or the period under concern. Since Borts (1960), many regional economists have adjusted the neoclassical assumptions in order to make the model more realistic. In due course every single assumption has been changed and manipulated in order to reflect reality better. By relaxing some of these assumptions, it was possible to achieve completely different outcomes of the model, in particular to explain divergence rather than convergence. However, alternative models, like the cumulative causation model ${ }^{5}$, were also capable of generating divergence results. This obviously raised the question if an alternative, non-neoclassical model would not be more feasible to explain the observed outcomes (Richardson 1973, 1978a, 1978b).

In the same way adjustments were made to incorporate space and distance in a neoclassical growth model. However,

"although the neoclassical model may be modified or manipulated to provide a reasonable replication of the regional growth process, the spatial aspects of regional analysis reveal the limitation of the basic neoclassical model. The neoclassical growth analyst may choose to remain faithful to his traditional methodology, but alternative frameworks can more easily cope with the complication of space" (Richardson, 1978b, p. 143).

To come back on the argument made in the beginning of this section, the first step to be made to be more realistic with respect to space and distance, would be to alter the reasoning with respect to knowledge diffusion. The neoclassical way of regarding knowledge diffusion to be immediate should be replaced by an alternative idea like slow diffusion or (as illustrated in the next section) no diffusion at all.

\section{Cumulative causation}

This section will outline two 'objections' to the traditional neoclassical growth theory discussed by Kaldor (1975). Firstly, Kaldor states that the traditional neoclassical theory excessively emphasizes the importance of resource allocation and the idea that differences

\footnotetext{
${ }^{4}$ See for instance recent tests carried out by Barro and Sala-i-Martin (1991, 1992). Barro and Sala-iMartin (1991) show patterns of convergence in regional per capita income levels across 73 regions of Western Europe since 1950. In their 1992 study they present evidence for the hypothesis of convergence in regional per capita incomes across the 48 contiguous U.S. states. The authors explicitly state that their tests give evidence for the hypothesis that poor regions grow faster than rich ones ( $\beta$-convergence), or, the hypothesis of convergence in the levels of per capita income and product.

${ }^{5}$ See next paragraph.
} 
in resource endowments between regions explain the differences in regional growth rates. Secondly, he objects to the fact that the neoclassical model assumes constant returns to scale - and therefore, when taking all other assumptions of the neoclassical model into consideration, perfect mobility of knowledge - which should be replaced by increasing returns to scale. According to Kaldor (1970, 1975), technology is immobile. By elaborating these two points in the subsequent paragraphs, the cumulative causation model will be explained.

With regard to his first objection to the neoclassical framework, Kaldor (1970, 1975) stresses that differences in resource endowments still do not explain why industries are located in certain regions and not in other regions. He argues that to a certain extent, the neoclassical reasoning is correct, namely in the case of 'land-based' activities, which depend on climatic and geological factors. However, with respect to industrial activities, one cannot attribute the differences in development among regions to differences in resource endowments ${ }^{6}$. Differences in resource endowments originate from differences in economic growth, but they also cause economic growth (Kaldor, 1970). These two effects cannot be separated. In other words, the resources for manufacturing are endogenous, in contrast to the exogenously determined resources for land-based activities. As Kaldor puts it: "It is as sensible - or perhaps more sensible - to say that capital accumulation results from economic development as that it is a cause of development" (Kaldor, 1970, p. 339). The idea that economic growth causes productivity growth is often referred to as the Verdoorn-Kaldor law. It is this relationship that could contribute to the explanation of divergent growth of regions, according to Kaldor (1970). However, to explain the Verdoorn-Kaldor law, the existence of increasing returns to scale has to be acknowledged first.

According to the Verdoorn-Kaldor law, economic growth causes growth of productivity, because of static and dynamic economies of scale. Economies of scale can be divided into two groups. First, economies resulting from large-scale production, referred to as static economies of scale, such as for instance the further division of labour at the individual plant level. A second group of economies of scale originates from "the insight that the spatial concentration of economic activity can produce externalities" (Malecki and Varaiya, 1986). This group, referred to as dynamic economies of scale, consists of cumulative advantages that originate from the growth of the industry itself, like learning-bydoing and "the development of skill and know-how; the opportunities for easy communication of ideas and experience; the opportunity of ever-increasing differentiation of processes and of specialisation in human activities" (Kaldor, 1970, p. 340).

A related concept stemming more explicitly from the field of regional studies, is that of agglomeration economies, partly overlapping with the previous idea. The general idea behind the agglomeration economies is that the environment of the firm has an influence on the output of the firm. A spatial concentration of economic activity and people in the environment of a certain firm generates positive effects on the productivity of this firm, because, for instance, the opportunity for communication of ideas and experience is much larger. In this respect, also the presence of a research institute or a

\footnotetext{
${ }^{6}$ Here, resource endowments consist of endowments of capital, in which capital mean both "the plant and machinery, and human skills, resulting from education" (Kaldor, 1970, p. 339).
} 
university could generate positive external effects for the firm ${ }^{7}$. In short, agglomeration economies are everything what induces people and economic activities to cluster together (Richardson, 1978a).

In a simple model, Malecki and Varaiya (1986) represent agglomeration economies by letting output be determined by a Cobb-Douglas equation which is multiplied by an additional term, denoted by $D^{a}$. The variable, $D$, represents the effects of urban density or concentration on output. If the parameter $a$ is positive, it indicates agglomeration economies. On the other hand, if $a$ is negative, this would indicate congestion effects. From this simple model it can easily be seen that "agglomeration economies imply that the same capital equipment and labour in a plant operating in a larger urban environment will produce more than the plant in a smaller urban environment" (Malecki and Varaiya, 1986, p. 632).

According to the Verdoorn law (Verdoorn, 1949) a positive relation exists between the growth of productivity, measured by the rate of growth of output per employee and the growth rate of employment. Later Kaldor (1967) modified this reasoning by replacing employment growth by output growth. The resulting relationship became known as the Verdoorn-Kaldor law.

In the regional literature a specific interpretation is given to the Verdoorn-Kaldor law. For this law to be true, according to regional economists, it has to be assumed that "the increased investment resulting from higher growth in a region is located in the same region" (Malecki and Varaiya, 1986, p. 632), i.e. because a certain region experiences higher growth, investment in the same region grows. Part of the investment will be devoted to research and development (R\&D). The benefits of this increased R\&D-investment are only reaped in this very same region, thus only in this region productivity grows. This in turn will cause a rise in the output of the region, i.e. the region will experience growth. In this process, there is no diffusion of technology at all. The benefits of technical progress stay within the region that experiences the benefits of an increased investment, and therefore only this region shows an increase in productivity. This reasoning (referred to as the principle of circular and cumulative causation, Myrdal, 1957) explains why differences in productivity among regions may be persistent rather than a transitory state, as in the neoclassical model. As Kaldor (1970, p. 340) argues, the principle of circular and cumulative causation "is nothing else but the existence of increasing returns to scale in processing activities."

Of course, by assuming technology to be completely immobile, as opposed to the neoclassical view of complete mobility, Kaldor advocates another extreme and therefore unrealistic assumption. A theory based on imperfect mobility and slow diffusion of tech-

\footnotetext{
${ }^{7}$ It should be noted that the concept of growth poles as put forward by regional economists like Perroux (1955) and Boudeville (1966) is different from that of agglomeration economies. As Richardson (1978) explains clearly, "agglomeration economies mean the economies inducing people and activities to cluster together, not the effects of agglomeration. Although some agglomeration economies are size related, e.g. the provision of high-level urban services requiring a large population threshold, increasing size is more the result than a cause of agglomeration economies" (Richardson, 1978a, p. 156). Thus, the evolution of a growth pole is an effect of agglomeration economies. It is beyond the scope of this paper to discuss the growth pole theory of e.g. Perroux and Boudeville more explicitly. However, Kaldor (1975) also acknowledges the development of growth poles when he argues that "industrial development tends to get polarized in certain "growth points" or in "success areas," which become areas of vast immigration from surrounding centers or from more distant areas, unless this is prevented by political obstacles" (Kaldor, 1975, p. 356).
} 
nology might approach reality much more. The next section will introduce some theories which stress this point of view.

\section{Imperfect diffusion}

How do innovations diffuse over space? Traditional diffusion theory does not consider this question, but instead focuses on diffusion over time. Inspired by natural sciences (like epidemiology) and sociological thinking (with concepts like 'spread by contact'), economists devoted attention to the study of S-shaped curves as a representation of the diffusion of knowledge over time. A number of approaches are concerned with diffusion over time. Firstly, the epidemics model, in which diffusion was thought to have the same characteristics as the spread of an epidemic disease. During the early stages of the process the spread of innovation will be slow, because the probability of one adopter contacting a potential adopter is still low. However, this probability will increase over time. Halfway the process a breakpoint occurs, due to the limited population of potential adopters the probability will decline again, until the saturation point is approached (the population has run out of potential adopters, i.e. every adopter who would want to adopt the innovation has adopted it) (Rosegger, 1980). This process can be described by a logistic diffusion curve.

The epidemics model had some drawbacks, which led to a set of improved models. In the probit model of David (1975), it was recognized that the group of adopters of an innovation is not homogeneous. There may be a difference in the profitability of adoption of a specific innovation among firms. In Davids model the adoption of the innovation will be profitable only for firms above a given size, (Coombs, Saviotti and Walsh, 1987). Davies (1979) also differentiates between adopters. In addition, he differentiates between two types of innovation, which lead to different shapes of diffusion curves. Another important flaw of the epidemics model was the neglect of the supply side. For the diffusion of an innovation it is essential that an innovation will be implemented and therefore that it is profitable to manufacture products embodying the innovation (Coombs, Saviotti and Walsh, 1987). In order to correct this deficiency, several models were developed, e.g. Stoneman $(1983,1984)$ and Metcalfe $(1981,1982)$.

However, a more appropriate set of theories with regard to the question analyzed in this paper, consists of the technology gap approach, which concentrates on diffusion over countries. These countries need not necessarily be geographically close to each other. Technology is regarded to spread to a country, because of the specific characteristics of that country. Geographic proximity does not play a role in this respect. The so called spatial factors like agglomeration economies and growth poles as used by geographers were not addressed in this set of theories. Only the geographic stream of researchers used these concepts. These authors regard diffusion as a purely geographical process. Space is a central concept in this set of theories.

\section{IV.1 Technology gaps; diffusion over countries}

After some early publications such as Gerschenkron (1962) and Abramovitz (1979), research on technology diffusion over countries was deepened during the 1980s. Economists started to realize the importance of space and diffusion over countries for the falsification 
of the assumption of perfect knowledge mobility, as used in the traditional neoclassical theory. As an alternative to the neoclassical model of (regional) growth, the technology gap approach was introduced. Within this approach the concepts of "catching up" and "falling behind" play an important role. By means of these concepts, the technology gap approach attempts to give an explanation for the differences in productivity rates between countries (or regions).

In contrast with the theory set out by Siebert $(1969)^{8}$ which assumes polarization, the catch-up analysis in its simplest form is based on the idea that eventually the per capita income levels and growth rates will show a tendency to converge. However, within the technology gap literature a variety of ideas is brought forward with respect to the specific way convergence is perceived. These will be discussed in the following.

The idea that underlies the technology gap approach is that a technological difference between countries (or regions), "opens up the possibility for countries at a lower level of economic and technological development to catch up by imitating the more productive technologies of the leader country" (Fagerberg, 1988, p. 439). Abramovitz (1986) argues that this catching-up process is conditional upon some specific factors, referred to as social capability and technological congruence. According to Abramovitz (1986), a country which is technologically backward but socially advanced has a large potential for rapid growth. If this country also possesses the means to realize this potential for catch-up, it will be able to converge towards the technological leader'.

As stated above, there are two factors that influence the potential for catch-up. The first one, referred to as social capability ${ }^{10}$ describes all the factors that facilitate the imitation of a technology, or the implementation of technology spillovers (Abramovitz, 1986). Social capability "relates to factors such as education, an appropriate financial system, labour market relations etc." (Fagerberg, Verspagen, Von Tunzelman, 1994, p. 5). The second factor that determines the extent to which a country (or region) has a potential for catch-up is called technological congruence. This concerns the extent to which the country is technologically near to the leader country, i.e. to which extent it is able to apply the technical features from the new knowledge. As Fagerberg, Verspagen, Von Tunzelman (1994) state, technological congruence is "referring to the assumption that technological progress depends on leader-country characteristics, and that backward countries - to implement leader-country technologies - need to emulate some of these characteristics" (Fagerberg, Verspagen, Von Tunzelman, 1994, p. 5).

In course of time the assumed convergence process - which is conditional on social capability and technological congruence - will generate a situation in which the technological backward countries (the followers) catch-up to a large extent with the technologically more advanced countries (the leaders). Thus, at the end of the process the two groups of countries (regions) have converged and there will emerge one large group

\footnotetext{
${ }^{8}$ See section IV.2.

9 Following Verspagen (1991) the realization of catch-up will close the technological gap between countries only to a certain extent. To establish a complete closure of the technological gap the research and development efforts in the backward country should be raised (post catching-up).

${ }^{10}$ The term 'social capability' was first introduced by Ohkawa and Rosovsky (1973). With this term they denoted "those factors constituting a country's ability to import or engage in technological and organizational progress" (Ohkawa and Rosovsky, 1973, p. 212).
} 
of countries (regions) in which every country (region) has the same technology and the same rate of growth.

Another idea with respect to catch-up was proposed in a theoretical study by Ames en Rosenberg (1963). In their study they introduce the idea that the backward country could leap frog and surpass the leader country. Thus, after some time the followers will not only catch up with the leader countries (or regions), but even take over the lead. So the old leaders have become followers. This situation will last for some time and then the group of followers will again take over from the leaders. This process will continue, merely because both groups will expose innovation and imitation qualities. So an interplay of these two forces exists: "innovation, which tends to increase economic and technological differences between countries, and imitation or diffusion, which tends to reduce them" (Fagerberg, 1988, p. 439). "In general the outcome of the international process of innovation and diffusion - (...) - is uncertain. The process may generate a pattern where countries follow diverging trends, as well as a pattern where countries converge towards a common mean" (Fagerberg, 1988, p. 439).

Next to these theoretical studies, empirical tests were carried out to show convergence or divergence. Among the large range of tests two groups can be distinguished. First, tests which aimed at demonstrating simple global convergence. Second, tests which tried to distinguish between groups of countries, where convergence occurs within a group but not between the groups.

One important study, using long run data was performed by Baumol (1986). In this study Baumol uses data for the period 1870-1978 (provided mainly by Maddison (1982)) to show convergence of productivities of sixteen industrialized countries.

In 1988, De Long provided a critical comment on this study. His main remark is that "Baumol's regression uses an ex post sample of countries that are now rich and have successfully developed" (De Long, 1988, p. 1138). This cannot provide a rightful basis for making conclusions about convergence within this group of countries, because the sample consists only those countries that have converged. Therefore, the sample of Baumol is biased. De Long establishes a new (unbiased) sample that consists of 22 countries that possessed all the potential to converge in 1870. Criterium for constructing this sample was the income (or estimates of the income) ${ }^{11}$ for several countries in 1870. Analysing the results indicates that there is no convergence. In some cases even divergence prevails.

In reply to this comment Baumol, Blackman and Wolff (1989) repeat their tests based on an ex ante sample, and they conclude that the results of several tests indicate that divergence exists up to 1860. After that small convergence groups appear which enlarge over time, but never get that large to include the whole 22 countries of De Long.

Another line of research was developed somewhat later in time by authors like Durlauf and Johnson (1992), who carried out empirical tests that indicated multi-group convergence. The central idea is that at the end of the convergence process there will be two (or more) groups of countries, identified by specific characteristics. One group will not catch up with the other, however, the countries within a group show convergence. This phenomenon is called local convergence.

Durlauf and Johnson (1992) found that, depending on the initial condition a country is in, with respect to its Gross Domestic Product (GDP) per capita and its illiteracy rate, it converges to countries with similar initial conditions. Thus, they found evidence for

${ }^{11}$ In doing this De Long mixes historical estimates from different sources. 
the existence of local convergence. Convergence of countries exists within one group, but not between the groups.

\section{IV.2 Diffusion over space}

Until the 1970s, with the exception of Siebert (1969), the economic literature paid attention to diffusion of knowledge over time and not over space. Spatial diffusion of knowledge was mainly considered by economic geographers and not by regional economists. As was argued by geographers, "diffusion of innovation over space occurs according to predictable patterns which fail (...) to penetrate all conceivable locations" (Richardson, 1973, p. 113). Siebert (1969) attempted to incorporate technology creation, application and spread into a neoclassical growth model. The main contribution of Siebert to economic thinking was that he assumed technology to be not perfectly mobile, but to diffuse slowly over time and space. This section will discuss the viewpoint of the geographers as well as the contribution of Siebert to this field in economics.

In the beginning of the 1970s, economic geographers had proposed the idea of diffusion of knowledge over space. The central idea is that inventions can take place everywhere across space, but they diffuse along specific paths. Broadly, a distinction between two types of diffusion processes can be made.

First, the general spatial diffusion model. The assumption was posed that economic growth, usually in the form of innovations, was to spread throughout a growth center's hinterland and to 'lower order' cities, (e.g. Darwent, 1969; Moseley, 1974; Todd, 1974; see Malecki, 1983). Thus, innovations were expected to spread among regions from one region to its neighbours and so on. This model is mainly used to study diffusion processes in underdeveloped regions. Empirical observation of undeveloped societies shows the following pattern with respect to diffusion of innovation. In most cases implementation of inventions takes place in the spacial surroundings of the original innovation centre. After the innovation has been implemented in a certain spatial neighbourhood of this innovation centre, the diffusion process halts. Therefore, smaller urban centres are not reached. "There is very little penetration into smaller urban centres and rural areas, especially when these are isolated from the main innovation centre" (Richardson, 1973, p. 126).

The contrary occurs in a hierarchical system of diffusion. This second type of diffusion process advocates that innovations spread from the place of invention to other large centres in the economy. As time passes the innovation will also reach hierarchical lower urban centres. One argument for this reasoning was given by Richardson (1978): "Larger cities are more likely to be receptive to innovations because of disproportionate concentration there of the innovation adopting elite (technologists, managers and R\&D specialists), a more favourable social structure and the location there of decisionmaking centres of large corporations." In this type of diffusion model, the most important factor determining the timing and rate of acceptance of a new technology was thought to be the region size (measured by population), because it represents the spatial concentration of entrepreneurs and industry as well as market potential, (Brown, 1981, see Malecki and Varaiya, 1986). Thus, the idea that "innovations spread among regions in a sequence that begins with larger, or more populous, regions and only later includes smaller regions" (Malecki and Varaiya, 1983, p. 634). This form of diffusion is mainly seen in developed regions. 
However, such a strict division cannot be drawn between spatial and hierarchical models when looking at the reality. It frequently occurs that in the beginning of the diffusion process the hierarchical model dominates, which with the passing of time is taken over by the spatial diffusion process. Hägerstrand (1966) states that

"the point of introduction in a new country is its primate city; sometimes some other metropolis. Then centres next in rank follow. Soon, however, this order is broken up and replaced by one where the neighbourhood effect dominates over pure size succession" (Hägerstrand, 1966, p. 40).

Thus, at first an innovation spreads depending on the size of the city or region (measured by the population), after a short period diffusion proceeds depending on the proximity of potential buyers. The period until the spatial diffusion process takes over from the hierarchical diffusion process might be very short. The process of spatial diffusion will occur at virtual the same time as hierarchical diffusion. For example, the place of introduction of a new product will be most often in a metropolitan city, because of hierarchical diffusion. After this first introduction, diffusion will, in all likelihood, develop simultaneously through the hierarchical line as well as spatially. The logic behind hierarchical diffusion would be that the economic risks are less in a larger potential market. However, the argument of spatial diffusion would be that the innovation might be imitated more easily by proximate places which would have a higher probability of exposure to it. (Robson, 1973).

In his study, Siebert points out that there are other factors, apart from a high population density and geographic proximity, which have an influence on the spread of knowledge. In his analysis he focuses on three main factors that influence the mobility of knowledge and determine the final specialization of a region.

Siebert concentrates his analysis on three basic ingredients for a perfect flow of knowledge, and shows that every ingredient encomprises imperfections. For a perfect transfer of knowledge about new inventions between regions it is needed to have a sender, a receiver and a system of communication. Each of these three factors can exhibit flaws that slow down the speed of knowledge transfer. First, with respect to the senders of information on new inventions, Siebert distinguishes two categories. One consists of government-supported research organizations and the other consists of private firms. With respect to inventions made by the first category, the mobility of knowledge is usually quite high, "because government-supported research organizations normally tend to communicate their research results" (in general basic research results), where private firms try to conceal their information, in consideration of their competitiveness ${ }^{12}$. The hypothesis that could be deduced from this aspect is that the more government-supported research institutions in a region, the greater is the mobility of knowledge. Related to this is the argument of Richardson (1973). He states that an indispensable factor for the spread of innovation in production techniques, processes and new managerial techniques "to lagging regions is the presence of high calibre managers, scientists, technologists and centres of the decision-making in these areas" (Richardson, 1973, p. 123). "Such potential adopters may be heavily concentrated in the core industrial regions of the economy (Ullman, 1958) and may also be relatively immobile, while the propensity for managers and technologists

\footnotetext{
${ }^{12}$ It should be noticed that knowledge generated by governmental institutions does not always have a high feasibility for private firms. Quite often private firms do need different kinds of research (more applied research) than is offered by the governmental research institutions (merely basic research).
} 
to be created domestically in the backward regions may be a function of the regions' past economic structure, social system and educational provision" (Richardson, 1973, p. 123).

The second factor highlighted by Siebert, is the receiver of the information on new innovations. These receivers (presumably firms) must be able and willing to implement a new invention in their normal procedures. Siebert argues that the greater the dissatisfaction with existing procedures in a region, the higher the willingness to adopt new methods. As Richardson (1973) puts it: "diffusion may be delayed if innovation requires new kinds of knowledge on the part of the adopter, new modes of behaviour or the coordinated efforts of different groups and organizations" (Richardson, 1973, p. 124). This argument was originally made by Mansfield (1968) and Day (1970). In addition to this argument, Siebert notes that new inventions - arising from basic research done by government research institutions - often need further research of private firms, which are unequally distributed over the regions. Therefore, "the existing spatial structure, i.e. the distribution of industry over space, determines the possible application of the new basic knowledge" (Siebert, 1969 , p. 71). For example, if there is a large concentration of firms in a certain branch of industry in a certain region, it is obvious that inventions which are technically related to the techniques used in this branch, will be adopted more than proportionally in this specific region. This only because of the fact that the industry, which is able to further develop the invention, is more than proportionally represented in this region. Another aspect of the same argument is that "many innovations are applicable only to an individual industry, and in this case the presence of that industry in a region is obviously a necessary precondition for the innovation to be adopted in the area" (Richardson, 1973, p. 124). So, the branch in the example is not only the one which is able to develop the invention, the branch is also the only one for which this invention has any potential benefits.

Thirdly, the communication between sender and receiver has to be efficient. Siebert makes a distinction between formal and informal communication. This distinction "affects the distribution of new basic knowledge." Firms which have informal contacts with research institutes may receive more information flows. Siebert argues that "the firms near the universities may be better and more quickly informed due to informal communication flows" (Siebert, 1969, p. 71). Thus, regions with many of those firms will have access to a higher amount of knowledge. In a paper of Jaffe (1989) empirical evidence was given in support of this reasoning. Based on an analysis of patent data it was concluded that "university research causes industry $R \& D$ and not vice versa. Thus a state that improves its university research system will increase local innovation both by attracting industrial R\&D and augmenting its productivity" (Jaffe, 1989, p. 968).

A clear distinction needs to be made between the realization of inventions on the one hand and the imitation on the other. Both influence the R\&D expenditures in a region, however, only the latter reflects the diffusion of technology. Looking at the realization of new inventions, differences between regions occur, because not every region will adopt new technical knowledge at the same rate, even if all regions have the same information on inventions. "An invention is likely to occur at one spatial point in a region" (Siebert, 1969 , p. 39), and will be realized depending on the extent to which the necessary requirements for an innovation are fulfilled in that region. With respect to the diffusion of technical knowledge on the other hand, innovations may be imitated less easy in certain regions. Factors that impede the mobility of knowledge in this respect are at first the 
transmission interval ${ }^{13}$, second, the patent system $^{14}$ and third, factors which are also concerned with respect to impeding the realization of inventions, like the availability of financial means to innovate or imitate; profit requirements; and the size of the firms in the region $^{15}$.

Based on set theory Siebert concludes that in the end a specialization of the regions will occur. Some regions will specialize in innovation, because they show the most favourable environment for innovating in their region, while others will specialize in imitation, or adoption. According to Siebert this will be the final state of the economy, so some regions are innovating and others are imitating, and again others are adopting the new inventions.

Related to this is his argument that the degree of mobility of knowledge will have no influence on this distribution. Innovation will be polarized irrespective of the degree of mobility of knowledge. The arguments for this view are the following. First, if information on new technical knowledge is immobile, there exists a tendency for polarization, because the new technical knowledge will be held as secret as possible by the firm which made the invention. Also the patent system may prevent widely spreading of innovations. Therefore only the spatial point where the invention occurred will realize the new technical knowledge.

One critical remark is in place, regarding this argument. Siebert abstracts here from the diffusion of an invention over space by multinational firms. It is obvious that a multinational firm will try to implement an invention done in one of its plants, in all its geographically dispersed locations. Consequently, Siebert would observe less polarization if he included the efforts of multinational firms, even when immobile knowledge is considered.

If, in the second case, information on new technical knowledge is perfectly mobile, a partially or totally polarized incidence of new technical knowledge may also be expected, according to Siebert, since not all spatial points will fulfil the necessary requirements for an innovation. There might be spatial points which have more favourable conditions for imitating than for the further development of a new invention, therefore these spatial points will not implement the new knowledge immediately, but wait for other regions to implement it. So technical knowledge will be polarized in those regions which have the most favourable environment for innovation. Thus even when there would not exist any information lag between the place of invention and the rest of the country (thus perfect mobility of knowledge would exist) there would still be an unequal distribution of technical progress.

\footnotetext{
${ }^{13}$ With a transmission interval is meant the time between the adoption of the innovation by one firm and the competitor of this firm knowing about it (Siebert, 1969). See also Friedman, J., A general theory of polarized development, the Ford Foundation, Urban and regional advisory programm in Chile, Santiago, Chile, 1967, p. 13.

14 The patent system of country has an influence on the whole country and not a specific influence on one certain region. However, a patent system can impede the mobility of knowledge and the scope for imitation.

${ }^{15}$ The size of the firms in a region has an influence on innovation and imitation. The presence of large firms can stimulate or impede innovation depending on different schools of thinking. Likewise, competition between firms is assumed to support or impede innovation (again depending on the view).
} 


\section{IV.3 Economic Geography}

In recent years, a combination of the above two streams of literature came forward, namely economic geography. Economic geography considers, from a macro economic point of view, the rise and growth of clusters of firms. Important authors in the economic geography literature are Krugman and Rauch. Krugman (1991) focuses on the interaction of increasing returns, transportation costs and demand to explain geographic concentration of production. In his reasoning geographic concentration will grow and persist, once established. His reasoning is as follows. Every manufacturer will choose one single location to serve the market, because of the existence of scale economies. In order to keep the transportation costs to a minimum, the manufacturer will choose a location with a large local demand. However, the local demand will be large precisely where the majority of manufacturers choose to locate. Thus there is a circularity that tends to keep a cluster of firms in existence once it is established (Krugman, 1991, p. 15). With respect to the geographic location of a new cluster, Krugman argues that clusters may arise at any location, dependent on historical events.

Rauch (1993) states that the tradeoff between inefficiency costs (higher production costs at the current location) and investment costs (generated by a location in a newly developing industrial area) determines the geographic location of industries. Therefore, some firms will stay in the old clusters, while others locate in new, rising clusters. In the same way as Krugman, Rauch argues that in principal, new clusters may rise at any location.

However, the economic geography does not attach great value to technology as an important factor of motivation for firms to cluster together. Krugman stresses the fact that the presence of technology spillovers is one out of three reasons which motivate industries to cluster geographically. Krugman applies the Marshallian distinction between three reasons for geographic localization, which are: first, the presence of a pooled market of workers with specialized skills. A second motivation of firms to cluster together is that "an industrial center allows the provision of nontraded imputs specific to an industry in a greater variety and at lower cost," (Krugman, 1991, p. 37). In the third place technology spillovers might play a role, because information flows more easily over small distances (present within an industrial center) than over larger distances. However, Krugman concludes that "forces for localization other than those involving high technology are quite strong", (Krugman, 1991, p. 53). In the philosophy of Rauch, technology spillovers are not mentioned explicitly in the reasoning.

The major contribution of economic geography is the general awareness of the importance of transportation costs as an factor influencing the geographical concentration. In early papers by Von Thünen (1826), Christaller (1933) and Lösch (1944), transportation costs were already taken into account as playing an important role, however, with the event of the neoclassical growth model, the factor of transportation was discarded, at least by economists. This new awareness of transportation costs opens possibilities for the government to influence the economic prosperity of a geographical area. The government investment on infrastructure as percentage of the GDP has declined in the OECD countries over the last 20 years (Toen-Gout and Jongeling, 1993). However, recently it has become clear that an efficient infrastructure is an essential condition for lasting economic growth. 


\section{$V$ The relation between diffusion of innovations and $R \& D$}

The above theories differ with respect to their assumption about knowledge diffusion, more specific, they differ in the extent they assume knowledge to spread over regions. However, all theories take as a point of departure the assumption that (at least initially) technology gaps between regions exist. In this section it will be examined what is to be learned from the above theories and what they can offer empirically. First, however, the problem occurs that the extent to which diffusion takes place in reality, is difficult to measure. The available data is mainly on $R \& D$ expenditures of regions. Therefore, this section will start by discussing what the term diffusion refers to. Furtheron in this section it will be examined what conclusions can be drawn based on the theories discussed until now, and how they can be tested empirically, using the available R\&D data.

Traditional economic thinking made a clear difference between $R \& D$ and diffusion of innovation. While technological progress was seen as the result of accumulated $R \& D$ capital stock, the actual diffusion was assumed to be instant across total capital (Soete and Turner, 1984, p. 613). However, the concept of diffusion is difficult to separate from $\mathrm{R} \& \mathrm{D}$. There is only a partial overlap between the concepts.

A division can be made between diffusion of new technological knowledge and diffusion of conventional knowledge. For the diffusion of new technological knowledge, R\&D is needed, while the diffusion of conventional knowledge is not necessarily accompanied by R\&D investments.

Diffusion of new technological knowledge occurs for a large part through assimilation of this technology into new products or processes. Every innovation builds upon existing technological knowledge. In using and assimilating conventional technological knowledge into new products and processes, knowledge diffuses geographically.

For example, the first washing machines were operated manually. Man power was needed to shake the drum with the dirty laundry. After that, electromotors were used to generate the power needed to shake the drum. Still a person had to switch the washing machine on and off, and therefore had to determine the time needed to clean the laundry. Today, this level of technology constitutes conventional technological knowledge. Such a washing machine is built with 'of-the-shelve' technology. It does not require much R\&D to produce it. For sake of the argument, such a washing machine is called a conventional washing machine. The diffusion of microprocessor technology was brought one step further by introducing chips into washing machines. Now it became possible to choose between several washing programs of your washing machine. The developer of this washing machine assimilated the new chip-technology, with the conventional knowledge of how to build a washing machine. $R \& D$ investments were needed to apply the microprocessor technology onto washing machines. By this example it is shown that the diffusion of new technological knowledge needs $\mathrm{R} \& \mathrm{D}$ investment. Therefore, the amount of R\&D expenditures gives an indication for the extent of this kind of diffusion.

A second argument with respect to the diffusion of new technological knowledge is related to multinational enterprises. New technological knowledge is often diffused by multinational organisations. Multinationals today are major players in a globalising economy, therefore a large part of $\mathrm{R} \& \mathrm{D}$ investments made by business enterprise can be attributed to multinational enterprises. As already mentioned in the former section, when an invention is done in one plant of the multinational (or in a geographically isolated R\&D department of the multinational), this invention will be diffused to all its 
geographical dispersed plants. Therefore, innovations generated by multinationals immediately cause diffusion of new technological knowledge. Thus, the amount of business R\&D expenditures - which mainly can be assigned to multinational enterprises reflects diffusion.

However, diffusion contains also the spread of conventional technological knowledge. For example, the production of the conventional washing machine can be put in several geographical locations, for example also in a country which never had any knowledge about building washing machines ${ }^{16}$. This example shows diffusion of a conventional 'of-the-shelf' technology, which can be bought and brought into use, without the need of many R\&D expenditures to implement it. Obviously, this kind of diffusion cannot be measured by the $R \& D$ investments, because $R \& D$ is hardly needed for diffusion along this path.

It can be concluded that diffusion cannot be measured unambiguously, at least not by the amount of R\&D investments. However, what can be measured are the causes of diffusion of knowledge, namely technology gaps between geographical places (regions). Is there any reason to assume that there exist technology gaps between geographical locations? The theories discussed in the first part of this paper offer some interesting hypotheses, which can and will be tested empirically.

First, neoclassical theory. This line of thinking assumes an immediate diffusion of technological knowledge, therefore differences in technological knowledge between regions will immediately cancel out. Following the neoclassical line of thinking, it would be expected to find no empirical evidence of technology gaps between regions. In course of time it became evident that the assumption of immediate diffusion is a very unrealistic one. Furthermore, suppose that immediate diffusion would be the right representation of the reality, this would not necessarily lead to the disappearance of technology gaps between regions. Differences in R\&D investments between regions could be the result of specialisation. There might be a region which, like every region, immediately has all available technological knowledge, but just does not want to or has no (financial) means to assimilate it into new products. Thus differences in R\&D expenditures between regions do not necessarily cancel out, they can also be the result of specialisation, however, the neoclassical theory does not examine this possibility.

Cumulative causation and imperfect diffusion, on the other hand, consider technology gaps between regions as the point of departure for their reasoning. The theory of cumulative causation continues by arguing that no diffusion of knowledge will take place, which will result in polarization. The $R \& D$ performed in one region will remain in that region, therefore the benefits of this $R \& D$ will only be reaped in this region. Theories of imperfect diffusion, on the other hand, proceed by arguing that diffusion will take place, although slowly. The speed of diffusion depends on certain supporting or impeding factors. In the end this will result in specialisation of regions in either imitation, adoption or innovation. Therefore, following these theories of cumulative causation and imperfect diffusion, it would be expected to find empirical evidence indicating the presence of technology gaps between regions.

Which regions will specialize in innovation according to the different theories? In other words, if empirical support is found for these differences, what factors are related to the relative innovativeness of a region? Following cumulative causation, the region which

\footnotetext{
${ }^{16}$ But did have the technological environment and infrastructure to be able to start producing.
} 
once has generated a small innovation, leading to an increase in productivity, will specialize in innovation. The reason is that increasing returns and agglomeration economies will provide cumulative economic growth in only that region.

Imperfect diffusion theories argue that the region which has a comparative advantage in innovation will specialize in innovation. The comparative advantage of a region can be generated by several factors, among others the financial means of the region, the population density, the economic activity and the geographical proximity to a university or any other form of higher education, (see section IV.2). These theories therefore lead to raising the hypothesis that the above factors have an influence on the $\mathrm{R} \& \mathrm{D}$ intensity of a region.

A final question which will be examined in the empirical part of this paper is: what will be the long term implications of the technology gaps between regions? Because both sets of theories (cumulative causation and imperfect diffusion theories) forecast polarization as occurring in the end - cumulative causation by the assumption that productivity in one region will lead to economic growth in only this region; and imperfect diffusion by specialisation - it is expected that differences between regions will persist also in the long run.

\section{Empirical operations}

The first part of this paper described a few theoretical explanations for the way knowledge diffuses over regions, i.e., for regional differences in innovativeness. A way to test for these regional technology gaps will be explored in the first section of this empirical part. The second empirical operation discusses the explanation of regional technology gaps by means of linear regressions. However, because of the short time series that are used in this section the regressions are cross-country. To get an indication of the long run consequences of the process of knowledge diffusion, the third and final empirical operation will test for convergence or divergence in $R \& D$ across regions by means of transition matrices.

All these empirical operations were conducted using the EUROSTAT regio database. With regard to the definition of a region some critical remarks are in place. In the empirical part of this paper the Nomenclature of Territorial Units for Statistics (NUTS) is used. Using this classification has certain known disadvantages. The classification reflects administrative units which differ in size, (Molle, 1980). Furthermore, a region defined by administrative boundaries does not necessarily reflect the area that would be enclosed by economic boundaries reflecting regions with similar economic characteristics, (Richardson, 1978). Moreover, such an administrative classification cannot even prevent that regions vary in administrative functions between countries, (Molle, 1980). However, the NUTS classification is often the only one for which consistent data is available.

\section{Herfindahl index}

Before investigating the possible causes of the regional technology gaps, it is useful to look at empirical evidence for these differences. Are there any patterns to be distinguished in the spatial distribution of $R \& D$ activities? In order to test for regional technology gaps the following null hypothesis could be put forward: technology gaps do not exist between 
regions, and hence R\&D is distributed identically to GDP and working population or any other indicator of economic activity.

An index that can be used to indicate whether a variable is distributed randomly or concentrated geographically is the Herfindahl index. It is defined as follows:

$$
H=\sum_{i=1}^{n} S_{i}^{2}
$$

Where $H$ denotes the Herfindahl index, and $S_{i}$ denotes the share of the variable of region $i$ in the total of the variable of the country. In order to measure innovativeness, data are used on R\&D expenditures as well as on R\&D employees. GDP and working population are used as indicators of economic activity. Considered here are only the regions on NUTS I level.

Two remarks need to be made with respect to the calculation of the Herfindahl index. First, because every country consists of a different amount of regions, the minimum value of the Herfindahl index differs for each country. To be able to still compare the countries, the Herfindahl index as used in this paper is divided by the minimum value it would have in the country under consideration. After this operation the logarithm is taken. Mathematically, this operation can be rewritten into the following equation:

$$
H F=\ln n+\ln \sum_{i=1}^{n} S_{i}^{2}
$$

Where $H F$ denotes the adjusted Herfindahl index. $S_{i}$ denotes the share of the variable of region $i$ in the total of the variable of the country. $n$ denotes the number of regions in a country.

The second remark concerns the data. For some countries a part of the data could not be completely broken down into regions. This data is not taken into consideration while computing the Herfindahl index. That is, the shares $S_{i}$ needed to compute the Herfindahl index are shares in the sum over the regions, instead of shares in the total of the country (the two may differ for some countries).

The variables for which the Herfindahl index was calculated, are the following. The prefix HF denotes that these variables are Herfindahl indexes. HFRBC refers to the Herfindahl index for the $R \& D$ expenditures in constant prices performed by business enterprise. HFRHC points to $R \& D$ expenditures in constant prices performed by higher education and HFRGC denotes government performed $R \& D$ in constant prices. The database for $R \& D$ employees is used to calculate the Herfindahl index for total personnel in business enterprise, denoted by HFPB, total personnel engaged in higher education, HFPH, and total personnel employed by the government. Finally, HFWP represents the Herfindahl index for the working population, whereas HFGDPC refers to GDP in constant prices.

Figure 1 shows on the vertical axis the Herfindahl index in 1991 for eight different variables ${ }^{17}$. The higher the score on the vertical axis, the higher the geographical concentration of the variable in a certain region. The horizontal axis displays the different countries for which the adjusted Herfindahl index could be calculated. The vertical dotted lines mark the separation from the next country.

\footnotetext{
${ }^{17}$ A few exceptions had to be made, because of the limited availability of the data. First, the variables HFWP and HFGDPC represent 1989 for Germany. Second, with respect to the R\&D data 1990 is taken for Portugal and 1989 for Germany.
} 
For the null hypothesis to be true, R\&D would have to show more or less the same rate of geographic concentration as the working population (WP) and Gross Domestic Product (GDP) or any other indicator of economic activity (which are assumed to be even distributed across regions). That is, the value of the Herfindahl index for R\&D would show approximately the same value as the Herfindahl index for WP and GDP.

A few points emerge from the figure. First of all, it is clear from the figure that the Herfindahl indexes for Portugal have relatively high values for each variable, as compared to the other countries. This observation can be explained by looking to the underlying data in more detail. It becomes evident that by far the most economic activity is found in region $\mathrm{RC1}$, which represents the continent and is therefore far out the largest region as measured by surface, as opposed to the other two Portuguese regions which represent relatively small islands. When the Herfindahl index is calculated on NUTS level II the surfaces of the different regions within Portugal are similar, therefore the results are better comparable. The results from this operation indeed indicate a significantly higher concentration for business R\&D compared to GDP and WP. ${ }^{18}$

A second point that is illustrated is that looking at the different variables for one country, the Herfindahl index for business enterprise $R \& D$ is considerably higher than

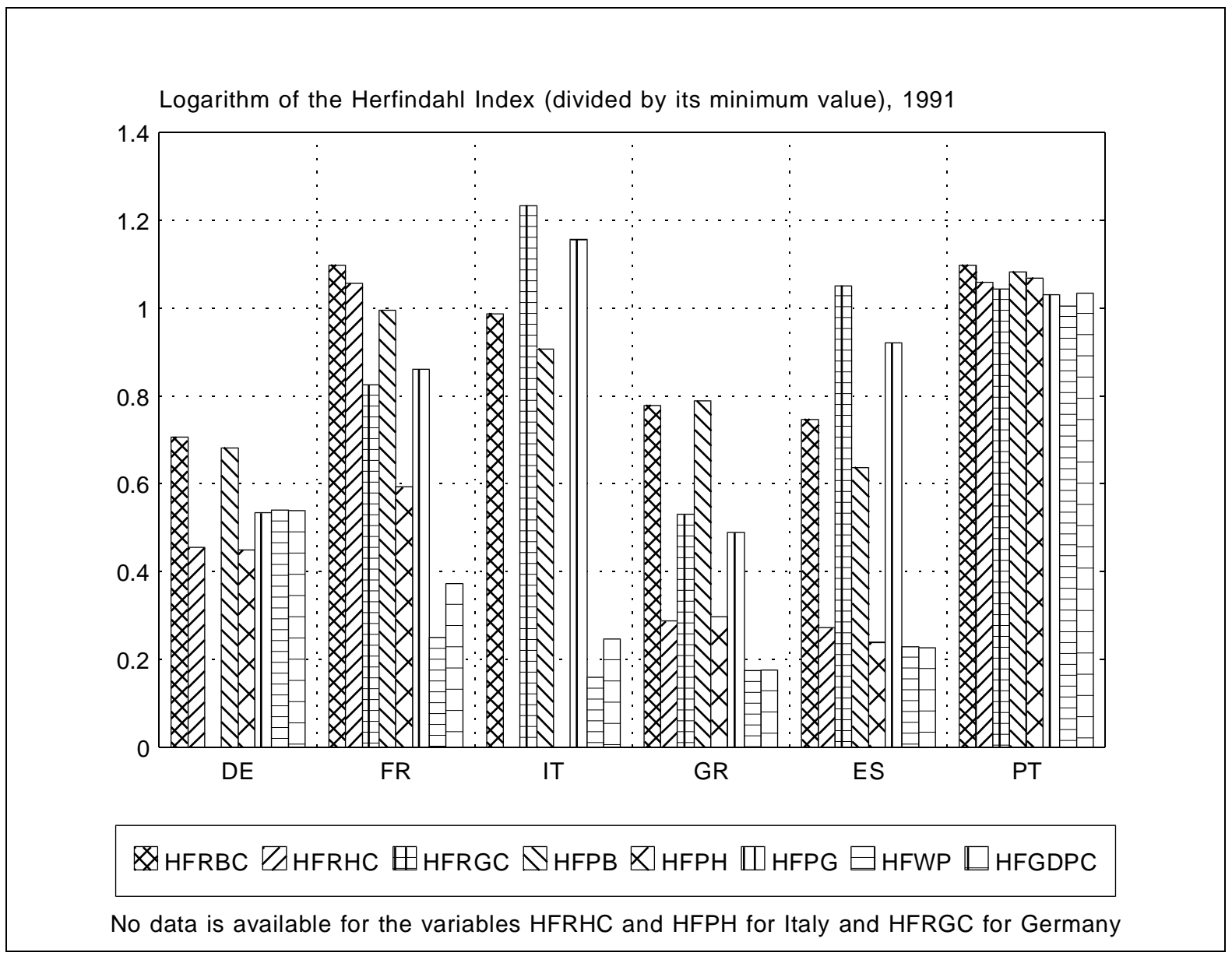

Figure 1

${ }^{18}$ See Appendix II. 
HFGDPC and HFWP. This is true for all countries. This points to the fact that R\&D performed by business enterprise is concentrated geographically to a larger extent than would be expected on basis of the geographical concentration of GDP or the working population.

A third point that emerges clearly from the figure is that in comparing business R\&D with higher education $R \& D$, the former is far more geographically concentrated for most countries. This is true for the $R \& D$ expenditure data as well as for the $R \& D$ employee data. This could be due to the fact that in determining the distribution of higher education across a country a large role is played by the government. In most cases the government of a country will pursue an equal distribution of e.g. universities across the country, which would account for a lower Herfindahl index and therefore a more even distribution of higher education R\&D.

Fourth, when taking government R\&D into consideration the results are less clear cut. From the figure it shows that some countries (like Spain and Italy) are characterized by a very high Herfindahl index with respect to government $R \& D$, i.e., government $R \& D$ is highly geographical concentrated. In those countries the Herfindahl index for government $R \& D$ is even higher than the Herfindahl index for business enterprise R\&D. However, other countries show a Herfindahl index which is below the one of business enterprise R\&D.

From these results it can be concluded that the null hypothesis should be rejected (at least with respect to business enterprise R\&D). Summarizing the conclusions from figure 1 , the empirical evidence indicates that $R \& D$ performed by business enterprise is certainly geographically concentrated. Therefore, it can be concluded that regional technology gaps do exist. This result is in accordance with what was expected based on cumulative causation and imperfect diffusion theories.

\section{Regressions}

To what extent are businesses engaged in $R \& D$ related to populated areas? And to what extent does a relationship exist between the presence of higher education and business enterprise in the same region? This is what will be explored in the following.

One hypothesis that was raised on basis of section IV.2 in which the geographer's approach is described, is that agglomeration in a certain region (that is a region with a high population density) will cause firms to establish $R \& D$ intensive businesses in that specific region. A second hypothesis, that is based on the analysis of Siebert, is that the presence of higher education in a region will attract $R \& D$ intensive firms. Using the EUROSTAT region database, several variables which proposedly would have an impact on the R\&D expenditures of business enterprise are tested for their significance.

One remark needs to be made with respect to causality. The aim of this section is primarily to give evidence for a relation between business $R \& D$ intensity and certain economic phenomena. The direction of the causality of the relationships cannot be demonstrated here, because not enough data was available data to make use of time series.

By multiple linear regression, a number of independent variables were combined in order to investigate their relationship on the amount of business $R \& D$ expenditure of a region. The dependent variable was measured by two different indicators. The first, IBP89, refers to data on $R \& D$ employees in the business sector. It is defined as the share of personnel engaged in $\mathrm{R} \& \mathrm{D}$ performed by business enterprise in the total working 
population of the region. The second indicator, denoted by IBR89, refers to the R\&D intensity of business enterprise, which is measured by R\&D expenditure performed by business enterprise divided by the gross domestic product (GDP).

With respect to the first hypothesis, the extent to which a region is populated is measured by the working population per area, denoted by WPA89. A second variable which proposedly has an influence on business R\&D is denoted by GWPC89, and is defined as gross domestic product in constant prices per head of the working population, (US prices, 1990). GWPC is used as a measure for productivity.

Second goal of the regressions performed in this part of the paper, is to determine to which extent higher education plays a role in inducing business $\mathrm{R} \& \mathrm{D}$. In order to test for this hypothesis, one variable indicating the amount of higher education in a region is added as a independent variable to the regression equation. The variable denoted by IHP89, is based on total personnel engaged in higher education, while the IHR89-variable is based on $R \& D$ expenditure data.

Using these different indicators, two different sets of regressions are presented (see Table 2). The first set includes simple linear regressions and has WPA89, GWPC89 and IHP89 (or IHR89) as explaining variables. The second set of regressions adds intercept and slope country dummies to the regression. Each set contains two pairs of regressions, one pair using $R \& D$ employment data and the other pair using $R \& D$ expenditure data. Each pair contains an equation using only the indicators for population density and increasing returns to scale as explaining variables, and an equation using an additional indicator for higher education.

Before discussing the regression results a remark has to be made with respect to multicollinearity. Multicollinearity refers to the feature that occurs when two explaining variables are interacting, and therefore correlated. In that case, the exact influence of one explaining variable on the dependent variable cannot be determined. If it would be the case that there is multicollinearity in the regressions performed here, this would make the estimation of the regression parameters less reliable. Usually multicollinearity is accompanied by large standard errors of the parameters, and parameters with wrong signs and values, which obviously makes their explanatory value useless. However, the characteristics of the relationship between dependent and explaining variables are maintained, i.e., a high value of the $\mathrm{R}^{2}$ statistic indicates that the regression specification is a good fit, although the individual regression parameters might be wrong in sign and value.

The following tables represent the correlation matrices for the $\mathrm{x}$-variables of the regressions performed in this section. Two matrices are shown here. The first, table 1A, refers to the regressors of IBP89. The second correlation matrix, table $1 \mathrm{~B}$, concerns the IBR89-regressors. The terms followed by a country name between brackets, indicate the correlation of the slope dummies of the respective variables of that country.

Based on these matrices it can be concluded that multicollinearity might certainly be a problem in assigning values to certain regression parameters. Especially the $\mathrm{x}$ variables with respect to Germany and Greece show large multicollinearity. This result is found in the employee as well as the expenditure data. The observed multicollinearity should be taken into account when analysing the regression results. 
Table 1A: Correlation matrix for the regressors of IBP89

\begin{tabular}{|c|c|c|c|}
\hline 48 observations & WPA89 & GWPC89 & IHP89 \\
\hline WPA89 & 1.0000 & & \\
\hline GWPC89 & $\begin{array}{l}0.40558 \\
0.92930 \text { (DE) } \\
0.75544 \text { (FR) } \\
0.96171 \text { (GR) } \\
0.73023 \text { (ES) }\end{array}$ & 1.0000 & \\
\hline IHP89 & $\begin{array}{l}0.37633 \\
0.93691 \text { (DE) } \\
0.70026 \text { (FR) } \\
0.86750 \text { (GR) } \\
0.83891 \text { (ES) }\end{array}$ & $\begin{array}{l}0.32212 \\
0.97570 \text { (DE) } \\
0.84665 \text { (FR) } \\
0.92092 \text { (GR) } \\
0.89865 \text { (ES) }\end{array}$ & 1.0000 \\
\hline
\end{tabular}

Table 1B: Correlation matrix for the regressors of IBR89

\begin{tabular}{||l|l|l|l||}
\hline \hline IBR89 (28) & WPA89 & GWPC89 & IHR89 \\
\hline WPA89 & & & \\
& 1.0000 & & \\
& & & \\
\hline GWPC89 & 0.73696 & & \\
& $0.91942(\mathrm{DE})$ & 1.0000 & \\
& $0.95859(\mathrm{GR})$ & & \\
& $0.67970(\mathrm{ES})$ & & \multirow{2}{*||}{} \\
\hline \multirow{2}{*}{ IHR89 } & 0.54061 & 0.45176 & \\
& $0.90339(\mathrm{DE})$ & $0.97032(\mathrm{DE})$ & \\
& $0.85605(\mathrm{GR})$ & $0.91629(\mathrm{GR})$ & \\
& $0.67136(\mathrm{ES})$ & $0.88159(\mathrm{ES})$ & \\
\hline
\end{tabular}

At this point, the results of the regressions will be discussed. The first regression indicates a significant WPA and GDPC, which moreover have the expected positive signs. In order to examine the effect of the presence of higher education on the R\&D intensity, the IHP89 variable is added to the regression specification. Including higher education results in positive WPA and GDPC coefficients, however, only IHP89 is significant in this relation. However, since there is a serious drop in observations between the two regressions it is not possible to determine whether the increase in R-squared is due to the drop in datapoints or the adding of the higher education variable. Therefore, in regression three, the first regression is repeated for the observations available in the second regression. By doing this the drop in observations is eliminated as a cause for the increase in R-squared. By looking at the (adjusted) $\mathrm{R}^{2}$ statistic in regression three it is shown that the IHP89 variable does not change the explanatory power of the regression equation.

The same regressions are repeated for the data on $R \& D$ expenditures. This also results in positive and significant values of WPA and GDPC. When higher education is 
added in the regression specification, this has the expected positive value and is also significantly different from zero ${ }^{19}$. However, the variable for population density loses its significance. Again one regression specification is added to be able to evaluate the effect of an addition of a higher education variable on the R-squared. As is shown by regression six, the most notable impact of the inclusion of the higher education variable in this data set, is the increase in explanatory power of the regression equation.

Introducing slope and intercept country dummies in the second set of regressions leads to another increase in the explanatory power of the regression equations. The regressions in equations seven and eight concern the employee data. Equation seven shows significant relations for Germany, Spain and Italy. However, the parameters with respect to Germany take an extremely high value, moreover, they have a negative sign. This effect is probably due to the multicollinearity found within this regression specification. When the higher education variable is added in equation eight, the total number of observations drops from 76 to 48 , due to the lack in data for Italy. The regression specification for Germany stays significant, while Spain loses the explanatory power of the intercept dummy for GWPC. This might also be the effect of the observed multicollinearity. It is shown in both regressions that R-squared is quite high. Therefore it can be concluded that the regression specification fits the data quite well.

Regarding equation nine and ten, the use of $\mathrm{R} \& \mathrm{D}$ expenditure data generates similar results. However, using this data set reduces the number of observations severely, because of the lack of business R\&D expenditure data for Italy and higher education data for France. When care is taken for the reduction in the degrees of freedom, equation nine shows a significant relations for Spain only. The results of the tenth equation suggest that multicollinearity plays a role again. The regression parameters are not significant on the $5 \%$ level for any country. However, the $\mathrm{R}^{2}$ statistic indicates that the regression specification is quite a good fit.

Summarizing the conclusions from table 2, we might say that the evidence of the positive influence of population density and economic activity on business R\&D intensity is quite strong. The statistical evidence for higher education as an additional explaining variable is also present. In this section the question was examined whether factors could be distinguished, which have an influence on the innovativeness of a region. Based on the theory three factors were brought forward, and their relation to innovativeness was tested empirically. As expected, population density, economic activity and geographic proximity to higher education, played an important role in relation to innovativeness.

\footnotetext{
${ }^{19}$ However, it needs to be said that the regressions presented in the first set were also repeated using logarithms. This worsened the results slightly, but still most important variables stayed significant. Population per area and GDP per capita were also examined as independent variables, instead of using Working Population and GDP per head of working population. They gave approximately the same results.
} 


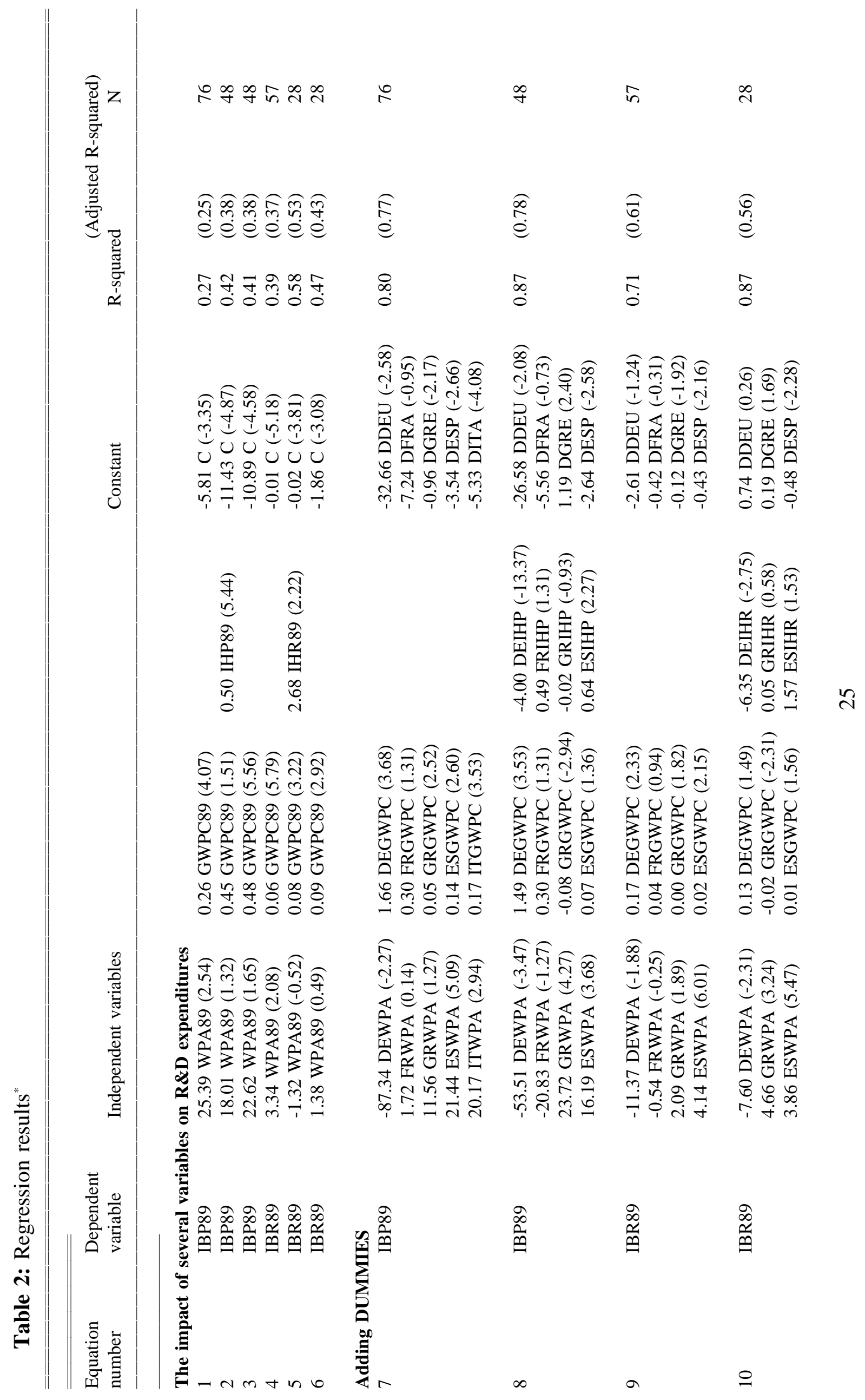




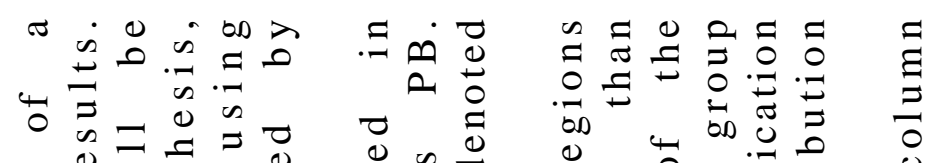

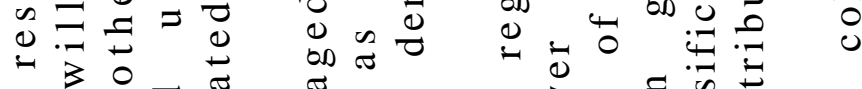

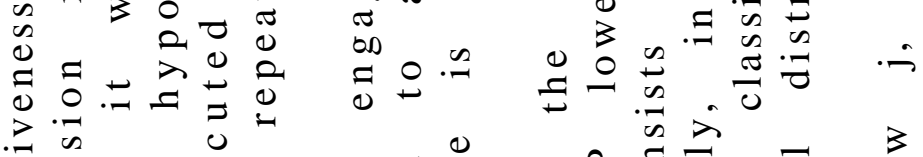

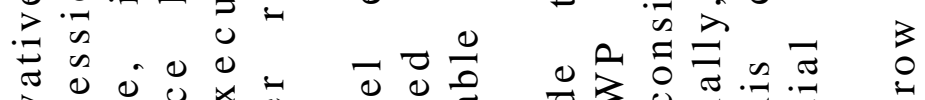

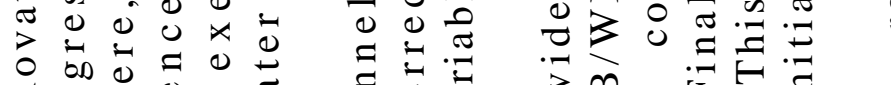

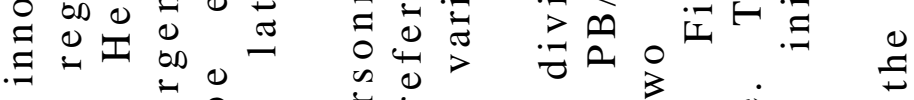

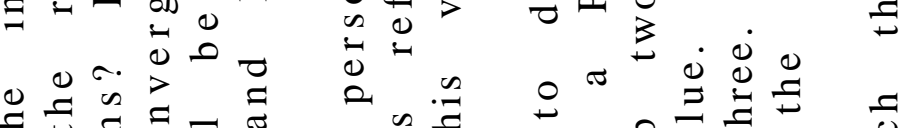

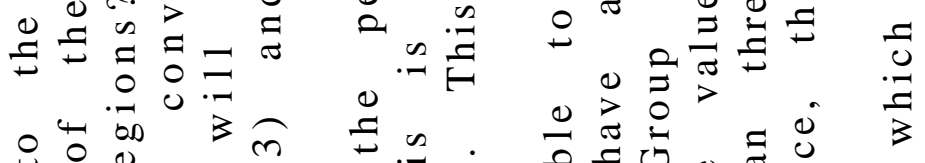

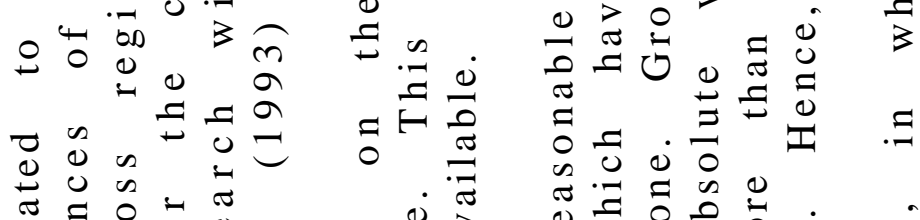

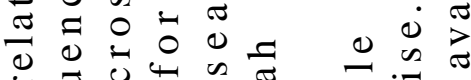

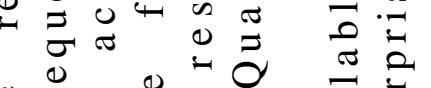

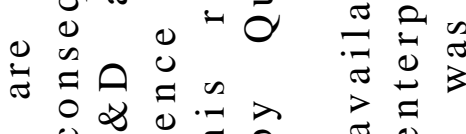

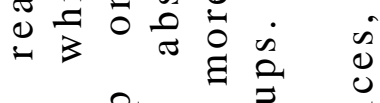

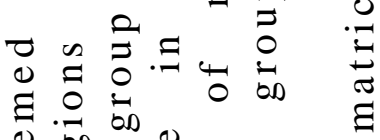

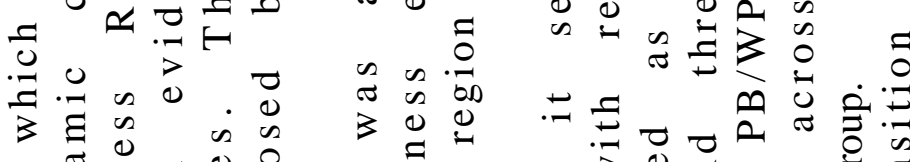

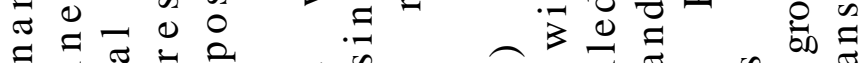

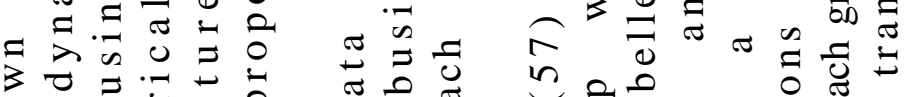

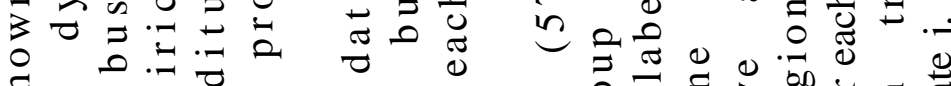

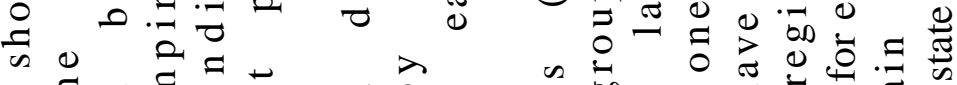

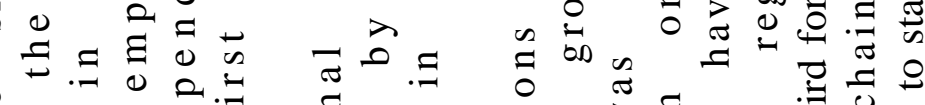

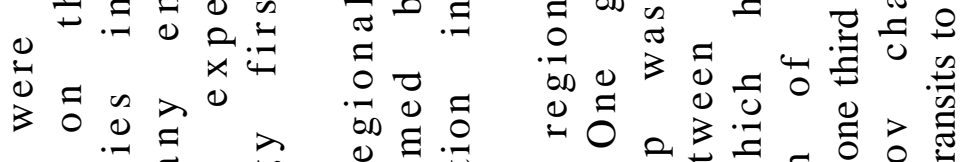

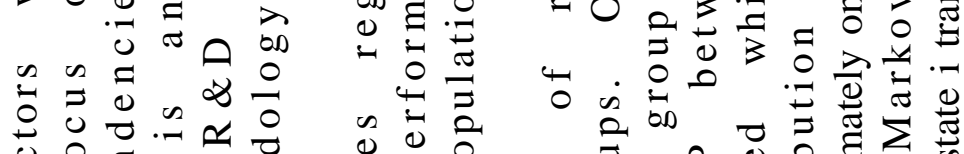

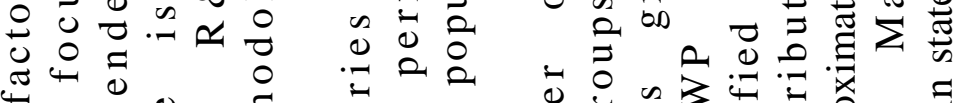

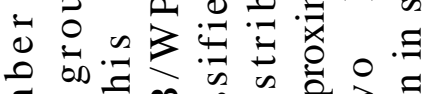

产

ฮั N

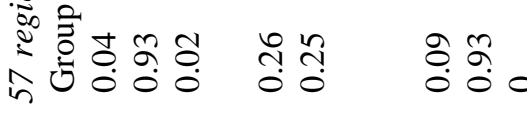
बें

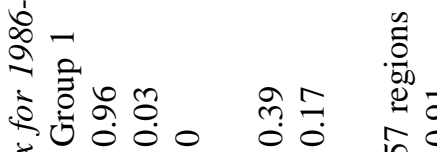

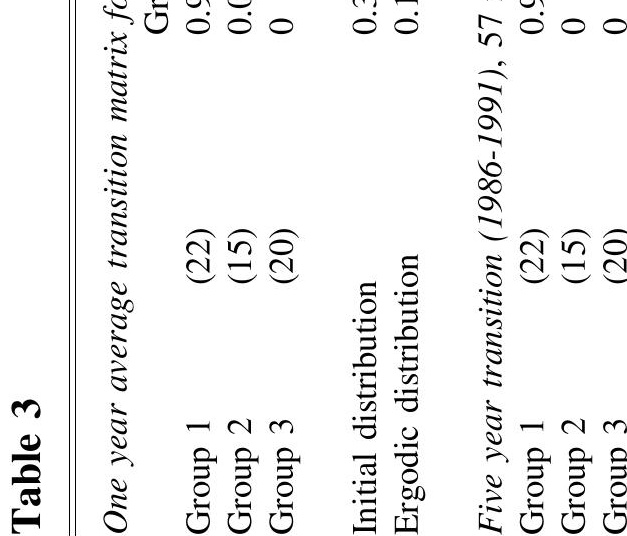


group 2 consisted of 15 regions, i.e., 15 regions had a PB/WP between one and three in absolute value. Of these 15 regions, 2.58 percent ended up in group 1 at the end of the period (1991), i.e, in the group of which the PB/WP rate had declined. Only 4.19 percent ended up in group 3, and thus had an PB/WP of more than three in absolute value. Thus, out of group 2 a larger percentage caught up (with the regions of group 3), than fell behind (to group 1).

In the one-year average transition matrix it can easily be seen that all diagonal elements are very close to one and for the first state off the main diagonal all elements are unequal to zero. This result indicates that there is a low transition speed. A simulation showed that the final distribution is only reached after hundreds of years.

From the ergodic distribution, which is given in the last row of the first panel of table 3, two points emerge. First, compared to the initial distribution (a method indicated by Neven \& Gouyette, 1995) it becomes clear that a large part of the regions in the low R\&D group (group 1) has moved to a higher R\&D group. In the initial distribution this group (group 1) was still the largest of the three. In the long run this group will become the smallest one. Also the group 2 becomes smaller in the long run. The benefits are reaped by the third group, which has the largest absolute value of PB/WP. In the final distribution this group becomes the largest.

Second, complete convergence would be indicated by a distribution in which only one group prevailed (a method suggested by Quah (1993)). This is not the case in the one

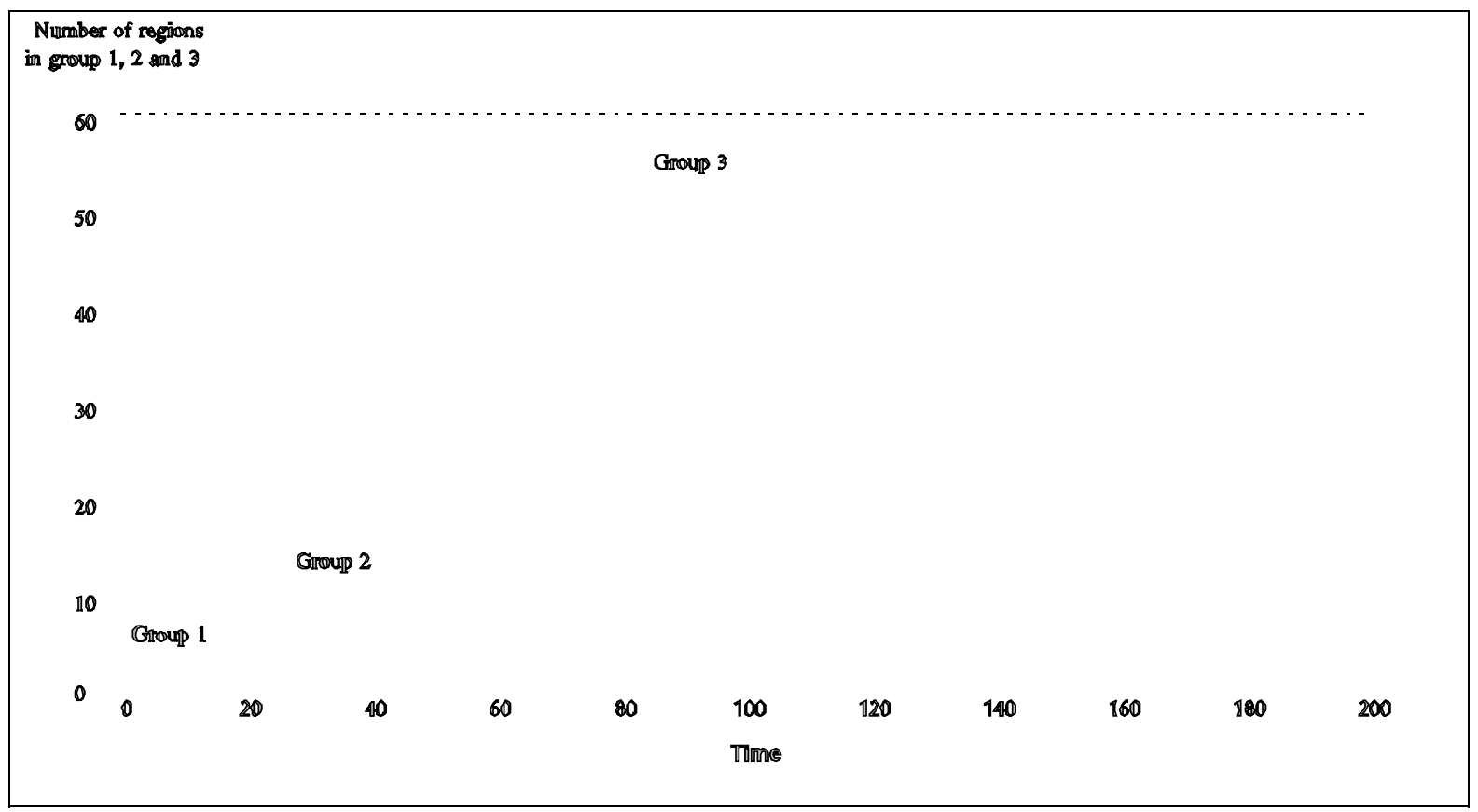

Figure 2

year average transition matrix. The results indicate that in the end three groups of different sizes prevail. In the long run there is a tendency for most regions to end up in group 3.

In the five-year transition matrix (see the second panel of table 3 ) the distribution over the groups in 1986 is compared with the distribution in 1990. This panel also shows diagonal elements which are equal to one, or almost equal to one. So again this is an indication of slow diffusion. It can also clearly be seen from the matrix that in the final distribution only the third group persists. The reason for this is that approximately 6.67 
percent of the regions in group 2 will transit to group 3. However, once in the third group, a region will stay in the third group (the non-diagonal elements in the last row of the matrix are equal to zero). This result would be an indication of convergence. However, since the speed of transition is very low the three groups mentioned above will remain present for a considerable period (see Figure 2).

In this respect it is important to mention that the ergodic distribution of a transition matrix only provides a characterization of the tendencies as embodied in the present configuration of the regions. The final distribution is not a forecast of what will happen, because all kind of disturbances over time - like changing government policies or unforeseen events (see Quah, 1993) may cause deviations in the dynamics and therefore in the final distribution.

The theories discussed in the first part of this paper predicted polarization to occur in the long run. This is also clearly indicated by the one year average transition matrix. In the long run three groups will prevail, one having a high R\&D intensity (this would be the largest group), a group with a low R\&D intensity, and a group of regions being in the middle. The five-year transition matrix demonstrates convergence, however, since this convergence will only occur after hundreds of years, the three groups will persist over a long period of time.

\section{Concluding remarks}

With the event of the application of the neoclassical model to regional economics, the assumption that knowledge would spread immediately became severely criticized. It was argued by several alternative theories that reality could be better explained by assuming knowledge to spread imperfectly or not at all.

In the theoretical part of this paper it became clear that these alternative models (cumulative causation and imperfect diffusion) consider technology gaps between regions as the point of departure for their reasoning. Therefore, following these theories, it would be expected to find empirical evidence indicating the presence of technology gaps between regions. The empirical evidence considered in this paper was based on an index of concentration. The empirical results from this concentration index suggested that technology gaps across regions are present in reality and therefore the results are in accordance with the cumulative causation and imperfect diffusion theories.

What are the factors that play a role in relation to innovativeness, i.e. are there certain characteristics of a region that make a region attractive for innovative activity? It was found empirically, that population density and economic activity are positively correlated to business R\&D intensity. Also some evidence was found for the presence of higher education in a region as an additional explaining variable. This is an important result, since the imperfect diffusion theories suggested that these factors would play a role in stimulating the innovativity of a region.

Finally, attention was directed towards the long run implications of the empirical relations found. Since the alternative theories predicted that technology gaps between regions would persist over time, it was investigated whether convergence or divergence would appear in the long run distribution of $R \& D$ across regions. The results of this operation suggested that, based on the present distribution, divergence would continue to exist. This is an important conclusion in the light of the ongoing European policy debate about "cohesion". For policy-makers it is important to know whether regions within the EC 
are either converging (neoclassical) or diverging. Divergence across regions exposes a task for the governments to provide economic support for the backward regions. this might be done in the form of aid programmes like the European Community's Regional and Cohesion Fund Policies. Another way in which the government could stimulate backward regions is by providing an efficient public infrastructure. Increasing the attractivity of a backward region for firms can be reached by means of geographically locating higher education in such a region. However, the question always posed in this context is whether this is an effective course to be followed. As can be concluded from regressions performed in the empirical part of this paper, a clear relationship exists between the presence of higher education in a region and the amount of business $R \& D$ performed in that same region. 
Appendix I: Regions used in the calculation of the Herfindahl Index*

$\mathrm{BE}$

Vlaams Gewest R51

Region Wallone R52

Brussel-Bruxelles R53

DE

Schleswig-Holstein $\quad$ R11

Hamburg R12

Niedersachsen $\quad$ R13

Bremen R14

Nordrhein-Westfalen R15

Hessen R16

Rheinland-Pfalz $\quad$ R17

Baden-Württemberg R18

Bayern R19

Saarland R1A

Berlin R1B

ES

Noroeste $\quad$ RB1

Noreste RB2

Madrid RB3

Centro (E) RB4

Este RB5

Sur RB6

$\begin{array}{ll}\text { Canarias } & \text { RB7 }\end{array}$

FR

Ile de France $\quad$ R21

Bassin Parisien $\quad$ R22

Nord-Pas-De-Calais $\quad$ R23

Est R24

Ouest R25

Sud-Ouest R26

Centre-Est R27

Méditerranée R28

Départements d'outre-mer $\quad$ R29

IT

Nord Ovest $\quad$ R31

Lombardia R32

Nord Est R33

Emilia-Romagna $\quad$ R34

Centro (I) R35

Lazio R36

$\begin{array}{ll}\text { Campania } & \text { R37 }\end{array}$

Abruzzi-Molise R38

Sud R39

Sicilia R3A 


\begin{tabular}{|c|c|c|}
\hline \multirow{2}{*}{\multicolumn{3}{|c|}{ saluegira }} \\
\hline & & \\
\hline & Voreia Ellada & RA1 \\
\hline & Kentriki Ellada & RA2 \\
\hline & Attiki & RA3 \\
\hline & Nisia Aigaiou, Kriti & RA4 \\
\hline \multicolumn{3}{|c|}{ 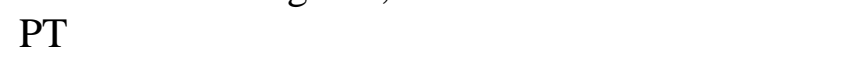 } \\
\hline & Continente & $\mathrm{RC} 1$ \\
\hline & Norte & $\mathrm{RC} 11$ \\
\hline & Centro (PT) & $\mathrm{RC} 12$ \\
\hline & Lisboa e Valo do Tejo & $\mathrm{RC} 13$ \\
\hline & Alentejo & $\mathrm{RC} 14$ \\
\hline & Algarve & $\mathrm{RC} 15$ \\
\hline & Açores & $\mathrm{RC} 2$ \\
\hline & Madeira & RC3 \\
\hline
\end{tabular}




\section{Appendix II}

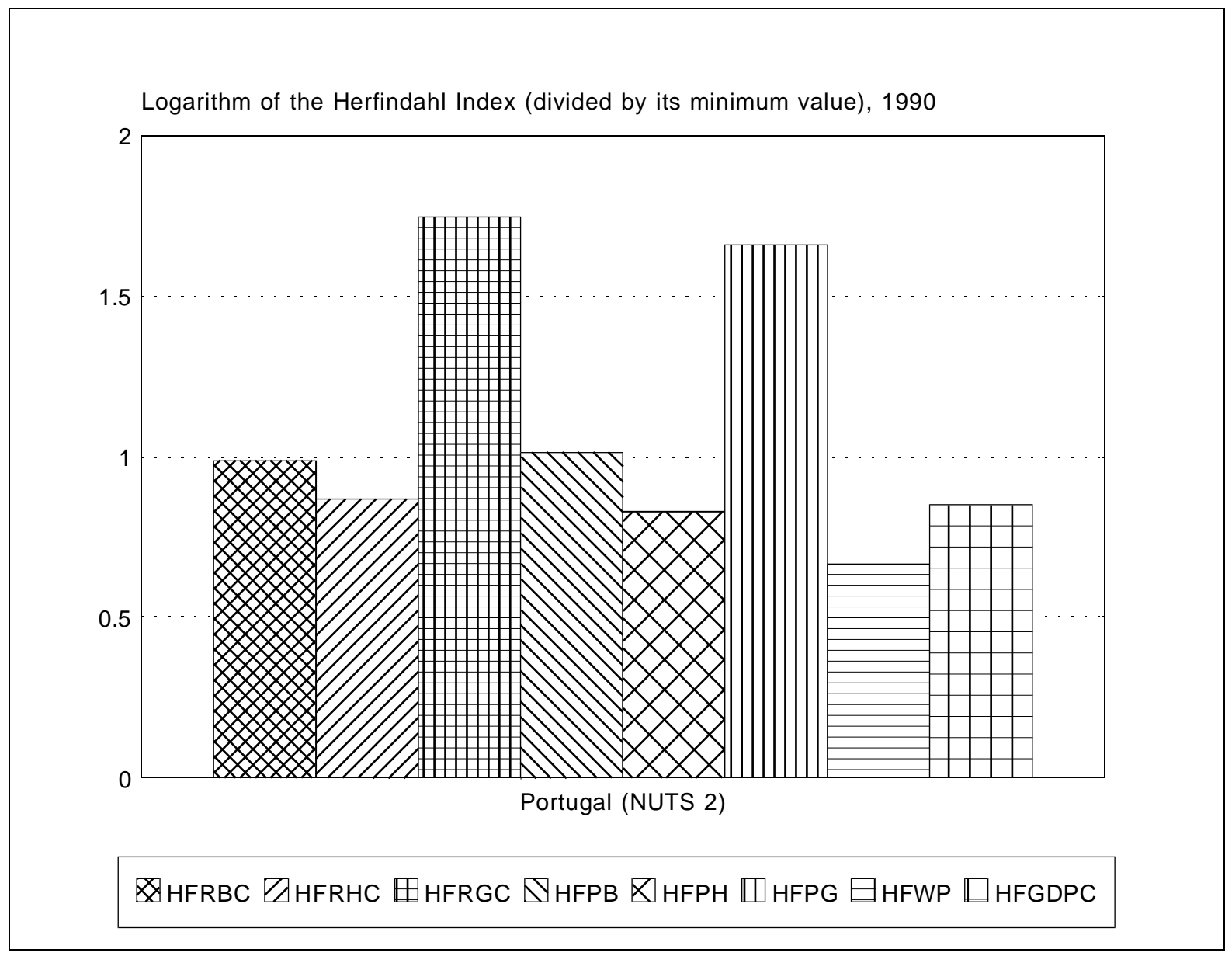

Figure 3 


\section{References}

Abramovitz, M., "Rapid growth potential and its realization: the experience of capitalist economies in the postwar period", in: E. Malinvaud (ed.), Economic Growth and

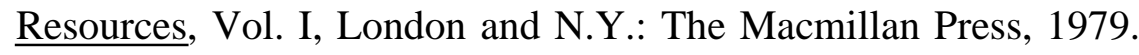

Abramovitz, M., Catching up, forging ahead, and falling behind, Journal of Economic History, vol.46, pp. 385- 406, 1986.

Ames, E. and N. Rosenberg, Changing technological leadership and industrial growth, Economic Journal, vol. 73, pp. 13-31, 1963.

Barro, R.J., Economic growth in a cross section of countries, Quarterly Journal of Economics, vol. 106, pp. 407-443, 1991.

Barro, R.J. and X. Sala-i-Martin, Convergence across states and regions, Brooking Papers Economic Activity, vol. 1, pp. 107-182, 1991.

Barro, R.J. and X. Sala-i-Martin, Convergence, Journal of Political Economy, vol. 100, pp. 223-251, 1992.

Barro, R.J. and X. Sala-i-Martin, Economic Growth, New York: McGraw-Hill, 1995.

Baumol, W., Productivity growth, convergence and welfare: What the long-run data show, American Economic Review, vol.76, pp. 1072-1085, 1986.

Baumol, W., S.A. Batey Blackman and E. Wolff, Productivity and American leadership: The long view, Cambridge, MA and London: The MIT Press, 1989.

Borts, G.H., The equalization of returns and regional economic growth, The American Economic Review, vol. , pp. 319-347, 1960.

Borts, G.H. and J.L. Stein, Economic growth in a free market, New York: Columbia University Press, 1964.

Boudeville, J.R., Problems of regional economic planning, Edinburgh: Edinburgh University Press, 1966.

Brown, L.A., Innovation diffusion, a new perspective, London and New York: Methuen, 1981.

Christaller, W., Central places in southern Germany, Englewood Cliffs, N.J.: Prentice Hall, 1933.

Coombs, R., Saviotti, P. and V. Walsh, Economics and technological change, London: Macmillan , 1987. 
David, P., Technical choice, innovation and economic growth, Cambridge: Cambridge University Press, 1975.

Davies, S., The diffusion of process innovations, Cambridge: Cambridge University Press, 1979).

Darwent, D.F., Growth poles and growth centres in regional planning: a review, Environment and Planning, vol. 1, pp. 5-31, 1969.

Day, R.H., A theoretical note on the spatial diffusion of something new, Geographical Analysis, vol. 2, pp. 68-76, 1970.

De Long, J.B., Productivity growth, Convergence and welfare:Comment, American Economic Review, vol.78, pp. 1138-1159,1988.

Durlauf, S.N. and P.A. Johnson, Local versus global convergence: across national economies, NBER Working Paper, No. 3996. Cambridge, MA: National Bureau of Economic Research, 1992.

Fagerberg, J., "Why growth rates differ", in Dosi, G. et al. (ed), Technical change and economic theory, London: Pinter Pub., pp. 432-457, 1988.

Fagerberg, J., Verspagen B. and N. von Tunzelman (eds), The dynamics of technology, trade and growth, Aldershot: Edward Elgar Publishing Limited, 1994.

Friedman, J., A general theory of polarized development, the Ford Foundation, Urban and regional advisory programm in Chile, Santiago: Chile, 1967.

Gerschenkron, A., Economic backwardness in historical perspective, Cambridge: The Belknap Press of Harvard University Press, 1962.

Hägerstrand, T., Innovation and diffusion as a spatial process, Chicago: The university of chicago Press, 1966.

Jaffe, A., Real effects of academic research, American Economic Review, vol. 79, pp. 957970, 1989.

Kaldor, N., The case for regional policies, Scottish Journal of Political Economy, vol. 17, pp. 337-347, 1970.

Kaldor, N., What is wrong with economic theory, Quarterly Journal of Economics, vol. 89, pp. 347-357, 1975.

Krugman, P., Economic geography and trade, Cambridge, MA and London: The MIT Press, 1991. 
Lösch, A., The economics of location. Translated by W.G. Woglon from 2nd revised edition, New Haven, Conn.: Yale University Press, 1954.

Maddison, A., Phases of Capitalist Development, Oxford N.Y., Oxford University Press, 1982.

Malecki, E.J, Technology and regional development: a survey, International Regional Science Review, vol. 8, pp. 89-125, 1983.

Malecki, E.J. and P. Varaiya, "Innovation and changes in regional structure", in: Nijkamp, P. (ed), Handbook of regional and urban economics, Amsterdam: North-Holland, vol. 1, pp. 629-645, 1986.

Mankiw, N.G., Romer, D. and D.N. Weil, A contribution to the empirics of economic growth, 1992.

Mansfield, E., The economics of technical change, New York: W.W.Norton, 1968.

Metcalfe, J.S., Impulse and diffusion in the study of technical change, Futures, vol. 13, pp. 347-359, 1981.

Molle, W., Regional disparity and economic development in the European Community, Farnborough, England: Saxon House, 1980.

Moseley, M.J., Growth centres in regional planning, Oxford: Pergamon, 1974.

Myrdal, G., Economic theory and under-developed regions, London: Gerald Duckworth \& Co. LTD., 1957.

Neven, D., and C. Gouyette, Regional convergence in the European Community, Journal of Common Market Studies, vol. 33, pp. 47-65, 1995.

Ohkawa, K. and H. Rosovsky, Japanese economic growth, Stanford, CA: Stanford University Press, 1972.

Perroux, F., "Note sur la notion de pôle de croissance", Économie Appliquée, vol. 7, pp. 307-320, 1955. Translated in: Livingstone, I. (ed), Economic policy for development, Baltimore: Penguin, pp. 278-289, 1971.

Quah, D., Empirical cross-section dynamics in economic growth, European Economic Review, vol. 37, pp. 426-434, 1993.

Rauch, J.E., Does history matter only when it matters little? The case of city-industry location, Quarterly Journal of Economics, vol. 108, pp. 843-867.

Richardson, H.W., Regional growth theory, London: Macmillan Press, 1973.

Richardson, H.W., Regional and urban economics, Hindsdale: Dryden Press,1978a. 
Richardson, H.W., The state of regional economics: a survey article, International Regional Science Review, vol. 3, pp.1-48, 1978 b.

Robson, B.T., Urban growth: an approach, London: Methuen \& Co LTD, 1973.

Rosegger, G., The economics of production and innovation, New York: Pergamon, 1980.

Siebert, H., Regional economic growth: theory and policy, Scranton, Pennsylvania: International textbook company, 1969.

Soete, L. and R. Turner, Technology diffusion and the rate of technical change, The Economic Journal, vol. 94, pp. 612-623, 1984.

Solow, R.M., Growth theory: an exposition, Oxford:Oxford University Press, 1970.

Stoneman, P., The economic analysis of technological change, Oxford: Oxford University Press, 1983.

Stoneman, P., "Theoretical approaches to the analysis of the diffusion of new technology", in: MacDonald, S. et al., The trouble with technology, London: Frances Pinter, 1984.

Thünen, J.H. von, Der isolierte Staat in Beziehung auf Landwirtschaft und Nationalökonomie, Hamburg, 1826.

Todd, D., An appraisal of the development pole concept in regional analysis, Environment and Planning A, vol. 6, pp. 291-306, 1974.

Toen-Gout, M.W., and M.M. Jongeling, Investeringen in infrastructuur en economische groei, Economische Statistische Berichten, vol. 13, pp. 424-427, 1993.

Ullman, E.L., Regional development and the geography of concentration, Papers and Proceedings of the Regional Science Association, vol. 4, pp.179-98, 1958.

Verdoorn, P.J., Fattori che regolano lo sviluppo della produttiva del lavoro, L'industria, vol. 1, pp. 3-10, 1949.

Verspagen, B., A new empirical approach to catching up and falling behind, Structural Change and Economic Dynamics, vol. 2, pp. 359-380, 1991. 